\title{
ARTICULAÇÃO ENTRE O CONSELHO TUTELAR E O SETOR SAÚDE NO ENFRENTAMENTO À VIOLÊNCIA INTRAFAMILIAR
}

\author{
CONNECTIONS BETWEEN CHILD GUARDIAN COUNCIL AND \\ THE HEALTH SECTOR AGAINST DOMESTIC VIOLENCE
}

\author{
ARTICULACIÓN ENTRE EL JUZGADO DE MENORES Y EL SECTOR SALUD \\ EN EL ENFRENTAMIENTO A LA VIOLENCIA FAMILIAR
}

\author{
Samira Valentim Gama Lira ${ }^{1}$ \\ Deborah Pedrosa Moreira ${ }^{2}$ \\ Gerarda Maria Araújo Carneiro ${ }^{3}$ \\ Ceci Vilar Noronha ${ }^{4}$ \\ Luiza Jane Eyre de Souza Vieira ${ }^{5}$
}

Resumo Este Estudo qualitativo focalizou a articulação do conselho tutelar com o setor saúde e o modo como se realizava essa parceria, durante os anos de 2013 e 2014. Participaram do estudo 45 conselheiros tutelares da Região Metropolitana de Fortaleza. Os dados foram construídos por entrevista semiestruturada e analisados em seus conteúdos. Os resultados apontaram para duas situações: o conselho tutelar parceiro do setor saúde e a inexistência de parceria. Esse descompasso entre as atuações do conselho tutelar e do setor saúde demonstra lacunas intersetoriais. Interlocução resolutiva da abordagem clínica e de garantia de direitos resultaria em menores custos e mais ações exitosas na redução da violência contra crianças e adolescentes.

Palavras-chave ação intersetorial; defesa da criança e do adolescente; sistema único de saúde; violência.
Abstract This is a qualitative study focused on the connections between the child guardian council and the health sector as well as the partnership during the years 2013 and 2014. The study included 45 tutelary councilors in the Metropolitan Region of Fortaleza, Ceará, Brazil. Data were built by semi structured interviews and their contents were analyzed. The conclusion pointed to the child guardian council is health sector partner and the lack of a partnership. This mismatch between the child guardian council and the health sector actions demonstrates intersectional gaps. Solving dialogue from a clinical approach and with the rights assurance would result in lower costs and more successful actions in reducing the violence against children and adolescents.

Keywords intersectoral action; child advocacy; unified health system; violence. 


\section{Introdução}

Assegurar a cidadania entre os povos tem sido pauta de acordos, declarações e pactuações mundiais (Organização das Nações Unidades, 1948, 1959). O cenário global testemunha a promulgação de documentos que preconizam igualdade, equidade e institui direitos que ainda não se conformam no cotidiano das sociedades.

No Brasil, com o advento da Constituição Federal e do Estatuto da Criança e do Adolescente (ECA) (1990), instituem-se garantias às crianças e aos adolescentes, em que são reconhecidos como sujeitos em desenvolvimento. Este marco ampliou os debates políticos e as articulações entre profissionais e movimentos sociais que lidam com esse grupo no intuito de se fazer cumprir a legislação brasileira.

Nessa lógica jurídica, o Sistema de Garantia de Direitos preconiza que os dispositivos legais sejam assegurados e os órgãos constituintes respondam, igualmente, por essa proteção integral. Defende que não é necessário que haja violação dessas conquistas para que os órgãos se mobilizem, articulemse intersetorialmente e responsabilizem-se em prover proteção a esse grupo (Brasil, 2009).

Paralelo aos avanços legais, implanta-se a Rede de Apoio e Proteção Integral e, nesse cenário, os Conselhos de Direitos da Criança e do Adolescente (CDCA), e os conselhos tutelares assumem papel singular no alcance e garantia dessas atribuições (Brasil, 1990; Conselho Nacional dos Direitos da Criança e do Adolescente, 2007).

Por sua vez, a atuação intersetorial é indispensável e envolve, também, a compreensão da indissociabilidade do setor saúde dos setores sociais, sintetizando a dinâmica de construção e gestão de políticas ancorada em referenciais éticos e valorativos da vida social. De modo formal e explícito, o setor saúde dialoga com as políticas, planos e resoluções que convergem para o enfrentamento às violências contra pessoas.

Dentre os dispositivos legais, destacam-se os direcionados aos grupos mais expostos aos riscos sociais: Politica nacional de redução da morbimortalidade por acidentes e violências (Brasil, 2001); Violência intrafamiliar: orientações para prática em serviço (Brasil, 2002); Plano nacional de enfrentamento da violência sexual contra crianças e adolescentes (Brasil, 2013); Linha de cuidado para a atenção integral à saúde de crianças, adolescentes e suas famílias em situação de violências: orientações para gestores e profissionais de saúde (Brasil, 2010); Portaria n. 104, de janeiro de 2011, que coloca as violências como o $45^{\circ}$ agravo de notificação compulsória (Brasil, 2011a); Metodologias para o cuidado de crianças, adolescentes e suas famílias em situação de violências (Brasil, 2014).

Em contraponto, a realidade social atesta a existência de situações-limite que interferem na garantia desses direitos e na articulação entre os setores que 
compõem, no plano formal, a rede de apoio e proteção social. Desse modo, mediante relatos de casos e um olhar ampliado de integrantes de conselhos tutelares da Região Metropolitana de Fortaleza, é analisada a parceria com o setor saúde. Este artigo elege, dentre as possibilidades da rede intersetorial, o setor saúde, pois acredita-se que é lócus privilegiado para a prevenção, identificação, atendimento e encaminhamento de casos de violência intrafamiliar que envolvam crianças e adolescentes.

Soma-se a este argumento a concepção de que o trabalho parceiro e compartilhado entre o conselho tutelar e os serviços de saúde ainda não se firma como uma relação cotidiana e consensual. Contrária aos princípios da intersetorialidade, esta parceria é percebida de forma contraditória, assistemática, imbuída de subjetividades e ingerências políticas partidárias, em detrimento de uma articulação científica, técnica, qualificada e ética.

Ante o exposto, este artigo analisa, com base na visão de conselheiros tutelares, a articulação do conselho tutelar com o setor saúde, na condução de casos de violência intrafamiliar.

\section{Percurso investigativo}

Extraído da pesquisa intitulada "Conselheiros tutelares: saberes e práticas no enfrentamento à violência intrafamiliar contra crianças e adolescentes", este artigo prioriza a abordagem qualitativa no intuito de elucidar como os integrantes do conselho tutelar apreendem a articulação entre o setor saúde e este órgão.

A pesquisa foi realizada na Região Metropolitana de Fortaleza, no estado do Ceará (Aquiraz, Caucaia, Chorozinho, Eusébio, Guaiúba, Horizonte, Itaitinga, Maracanaú, Pacatuba, Pindoretama e Fortaleza), nos anos de 2013 e 2014. A escolha por estes municípios justificou-se porque diversos órgãos trabalham em defesa da criança e do adolescente, como Ministério Público, Ministério da Justiça, Centro de Referência da Assistência Social (CRAS), Centro de Referência Especializado de Assistência Social (CREAS), Varas da Infância e da Juventude, Centro de Referência e Apoio à Vítima de Violência, Delegacia da Criança e do Adolescente, Centro de Defesa da Criança e Adolescente (Cedeca), Conselho Municipal de Defesa dos Direitos da Criança e do Adolescente (Comdica), hospitais, centros de Saúde da Família e conselhos tutelares. Alguns desses órgãos estão presentes nos municípios da Região Metropolitana de Fortaleza e outros sediados em Fortaleza e disponibilizam suporte aos municípios que não possuem esse serviço (Secretaria de Saúde do Estado do Ceará, 2011).

O ECA recomenda que cada conselho tutelar disponha de cinco conselheiros, o que assegura um total de 105 conselheiros na Região Metropolitana de 
Fortaleza, considerando que o município de Fortaleza possui seis conselhos tutelares e Caucaia, dois.

Por atenderem aos critérios de inclusão do estudo - ser conselheiro tutelar, estar em exercício do mandato e aceitar tomar parte da pesquisa -, participaram 45 conselheiros de 12 municípios da Região Metropolitana de Fortaleza. Houve recusas (44) justificadas pela alta demanda de serviço interno e externo, não resposta (9) a todo o instrumento e ausências (2) por férias e licenças diversas. Depreende-se que os conselheiros tutelares são pessoas-chave nos trâmites percorridos para assegurar os direitos de crianças e adolescentes, com potencialidades para interpretar os embates que circunscrevem as articulações setoriais, o que abona análises sobre as apreensões desses profissionais. Para a operacionalização da coleta de dados ocorreu agendamento prévio de dias e horários respeitados pela equipe da pesquisa.

Ressalta-se que esta participação foi efetivada após apresentação do projeto aos gestores municipais, explanação dos objetivos da pesquisa e de assinatura do termo de consentimento livre e esclarecido de cada participante. Os participantes responderam a um roteiro semiestruturado, autoaplicado e organizado em cinco blocos: características sociodemográficas e econômicas; características e/ou capacidade de articulação dos conselhos; instalações físicas e condições de trabalho; participação sociopolítica; e violência intrafamiliar. Neste artigo, optou-se por discorrer sobre o bloco que reporta as características e a capacidade de articulação dos conselhos tutelares com o setor saúde no atendimento de casos de violência intrafamiliar.

Justifica-se a escolha por este setor na medida em que os serviços de saúde constituem-se porta de entrada para as situações de violência, o processo de trabalho preconiza a vigilância à saúde e inclui a prevenção de agravos e promoção da saúde, e realiza vigilância epidemiológica, por meio do preenchimento da ficha de notificação e investigação individual de violência doméstica, sexual e/ou outras violências (Brasil, 2008, 2011 b; Gonçalves et al., 2015).

$\mathrm{Na}$ garantia do anonimato dos municípios e participantes atribuiu-se a letra ' $\mathrm{M}$ ' para identificar o município e ' $\mathrm{CT}$ ' para classificar o conselheiro tutelar, seguido por um algarismo arábico correspondente à ordem cronológica da coleta.

Ao interpor categorias predefinidas com as empíricas, realizou-se a análise de conteúdo, que busca compreender os significados no contexto em que as palavras são enunciadas, permitindo uma interpretação mais densa das falas e ultrapassa o alcance descritivo da mensagem e o emprego de técnicas quantitativas (Bardin, 2011).

Após análise desses conteúdos manifestos, emergiram categorias antagônicas, com subcategorias explicativas: articulação do conselho tutelar com o setor saúde - setor saúde é essencial e setor saúde como aproximação e base para o atendimento dos casos de violência; e inexistência de parceria entre o 
conselho tutelar e o setor saúde. A pesquisa foi aprovada no Comitê de Ética e Pesquisa da Universidade de Fortaleza com o parecer n. 456.783/2013.

\section{Características dos conselheiros tutelares}

Neste item descrevem-se atributos dos conselheiros tutelares e opta-se por uma síntese que vise a assegurar, da melhor forma possível, o anonimato. Posteriormente, discorre-se sobre as categorias e subcategorias com inflexões ancoradas na dinâmica da realidade e dos escritos acadêmicos.

Desse modo, os participantes tinham idade até 37 anos $(51,1 \%)$, eram do sexo masculino (57,8\%), casados (57,7\%), nascidos na Região Metropolitana de Fortaleza $(75,6 \%)$. Estudaram em escolas públicas $(88,9 \%)$, tiveram mais que oito anos de estudos $(68,9 \%)$ e a maioria não possuía nível superior $(73,3 \%)$.

Grande parte trabalha há pelo menos três anos $(20,0 \%)$, está no primeiro mandato do conselho tutelar $(62,2 \%)$, não tem outro vínculo empregatício $(53,3 \%)$ e trabalha menos de 48 horas por semana $(84,4 \%)$.

\section{Articulação do conselho tutelar com o setor saúde}

Os relatos dos conselheiros tutelares convergem para dois tipos de articulação com o setor saúde no atendimento dos casos de violência intrafamiliar contra crianças e adolescentes em seus municípios e reconhecem que a articulação com o setor saúde mostra-se essencial, bem como este setor aproxima e se constitui numa base na deflagração dos atendimentos de crianças e adolescentes envoltos em violências.

\section{Setor saúde é essencial}

Os conselheiros qualificam esta parceria como importante, principalmente, nos aspectos que os ajudam a lidar com o fenômeno. Reconhecem o quanto é necessário o atendimento desses casos pelo setor saúde, ao considerar a criança e o adolescente como seres em desenvolvimento. Acrescentam que esse setor se constitui em um canal de informação sobre os problemas familiares, ao firmarem a compreensão de que a atenção primária se apresenta como porta de entrada de uma população adscrita e estabelece vínculos com equipe multiprofissional. Reafirmam a presença e o papel singular do agente comunitário de saúde (ACS) na interlocução entre as famílias, serviços de saúde e conselhos tutelares.

Demonstram que uma das competências do setor saúde é responsabilizarse pelo diagnóstico desses casos. É atividade do profissional identificá-los e direcioná-los ao conselho tutelar para que esse órgão prossiga com o acompanhamento. Chama-se atenção para o fato de que os conselheiros tutelares, 
participantes do estudo, reiteram a compreensão das origens sociais das violências ao mencionarem e reforçarem que os serviços de saúde priorizam as 'lesões sangrantes'. Esta descrição evidencia-se nos conteúdos:

Este setor nos ajuda no combate à violência de nossas crianças e adolescentes, diagnosticando atos violentos, comunica ao conselho tutelar (M1-CT1).

É importante esta integração saúde e conselho. Pois são várias vezes que chega aos hospitais caso que compete a intervenção do conselho, no caso de espancamento de criança, abusos sexuais e outros (M2-CT2).

Os conteúdos manifestos não trazem à baila outras modalidades de violências, a exemplo da violência psicológica e da negligência, que, possivelmente, demandam uma escuta qualificada e uma atenção ampliada que abarquem a produção de singularidades individuais e familiares. Atentar à linha de cuidado, posta nos documentos oficiais, implica a ampliação das possibilidades de se visualizar outras modalidades de violência intrafamiliar com base em novos olhares dos profissionais de saúde, pautando-se em uma tríade que abraça a criança, o adolescente e o cuidado com as relações familiares.

Por outro lado, identifica-se afirmação que assevera 'estreito convívio' entre o conselho tutelar e o setor saúde, o que assegura a importância dessa parceria e expressa que todos estão empenhados em agregar a saúde e o bemestar do grupo infantojuvenil. Esta percepção vai ao encontro dos princípios que orientam a intersetorialidade.

(...) Além de ter um estreito convívio com o setor da saúde, tem uma importância, pois estamos sempre lutando pela saúde e o bem-estar da criança e do adolescente (M5-CT3).

A compreensão do papel do setor saúde pelos conselheiros tutelares participantes deste estudo é reiterada pelo Ministério da Saúde ao propor uma atenção integral à saúde de crianças, adolescentes e suas famílias com base em uma linha de cuidado que deve ser seguida pelos gestores e profissionais de saúde e de metodologias que contribuem com melhorias da atenção integral a esse grupo etário (Brasil, 2010).

Os profissionais de saúde quando se deparam com casos de violência intrafamiliar direcionadas às crianças e aos adolescentes devem preencher um protocolo de atendimento e encaminhar ao conselho tutelar, por ser um órgão que realiza atividades na garantia dos direitos, para que possa restabelecer o convívio entre famílias, comunidades e poder legitimado. Desse modo, é importante que o conselheiro tutelar identifique a parceria existente entre esses setores, garantindo que essa criança ou adolescente e sua família sejam 
acompanhados e percebam possibilidades de romper com o ciclo das violências (Moreira et al., 2013; Costa et al., 2015).

Compreender a violência sofrida pela criança ou adolescente é uma atividade complexa e delicada, principalmente para os profissionais de saúde que, rotineiramente, realizam ações no âmbito familiar e devem atentar aos sinais da violência. Ao identificarem um caso, devem acompanhar e proceder aos encaminhamentos necessários, desde a sua entrada no setor saúde - seja na atenção primária, ambulatório ou hospital - até o seguimento para a rede de cuidados e de proteção social (Brasil, 2010).

Em pesquisa realizada com 482 profissionais da atenção básica que atenderam algum caso de violência, mais de 50\% referiram ter realizado a notificação e a maioria dos participantes afirmou ter comunicado ao conselho tutelar. Dentre os profissionais que mais identificaram violências contra crianças e adolescentes, destacaram-se o médico $(48,9 \%)$, o enfermeiro $(48,8 \%)$ e o ACS $(41,6 \%)$. Na opinião de médicos e enfermeiros, a consulta foi o momento basilar para esses atendimentos, enquanto, para os ACS e técnicos de enfermagem, as principais fontes constituíram-se de informações de terceiros e durante a realização da visita domiciliar (Lima et al., 2011).

A importância da articulação dos serviços que compõem a rede de proteção integral a crianças e adolescentes em situação de violência intrafamiliar requer uma tarefa que só pode ser cumprida por um corpo articulado de ações, instituições, políticas e recursos que busquem com prioridade a garantia à vida, à saúde, à alimentação, à liberdade, ao esporte, ao lazer, à profissionalização, à cultura, à dignidade, ao respeito e à convivência familiar e comunitária (Rolim et al., 2014).

\section{Setor saúde como aproximação e base para o atendimento dos casos de violência}

As falas dos conselheiros tutelares, nesta categoria analítica, refletem a situação de alguns municípios que acreditam e defendem a parceria com o setor saúde para o enfrentamento e acompanhamento de casos de violência intrafamiliar contra criança e adolescente. No entanto, ponderam que a parceria encontra-se em construção e celebram a existência dessa aproximação entre os conselhos tutelares e o setor saúde.

Membros do conselho tutelar reconhecem a importância do trabalho em conjunto com o setor saúde e o consideram como um dos principais setores do município. Identificam casos de violência nas comunidades onde atuam, além de mencionar que muitos deles chegam ao hospital e necessitam da intervenção do conselheiro tutelar para o acompanhamento. Ao considerar as conjunturas, os respondentes compreendem que essa aproximação deva ser mais direta, contínua e com apoio irrestrito do setor saúde. 
Apesar de a maioria reconhecer a importância do setor saúde na intervenção desses casos, os conselheiros não relatam quais são os conteúdos pertinentes ao papel que o setor saúde deve exercer para o enfrentamento do fenômeno e contribuir para que se interrompa o seu ciclo. Essas colocações evidenciam-se nos seguintes discursos:

Acredito que todos os conselhos tutelares têm que trabalhar em parceria com a saúde, por haver muitos casos de violência contra crianças e adolescentes (M1CT3).

Porque acredito que é um dos 'órgãos' mais importantes do nosso município e tem que estar sempre presente nos equipamentos [sociais] (M1-CT2).

Nesta segunda expressão, os participantes da pesquisa possivelmente tenham feito alusão ao setor saúde, dadas as dimensões territoriais e as desigualdades brasileiras, compreendido como um importante setor estruturante da ocupação territorial e do desenvolvimento regional, e reconhecido, ainda, pela força motriz na geração de emprego e de riqueza para o país (Gadelha, Maldonado e Costa, 2012).

Importante afirmar que os diversos níveis de atenção dos serviços de saúde conformam-se num lócus privilegiado para receber os casos de violências intrafamiliares, principalmente por acolher essas demandas, em razão das lesões imediatas e das repercussões de médio e longo prazo desencadeadas por esses atos violentos.

Entretanto, no dia a dia, a comunidade percebe a oferta dos serviços de saúde 'restrita' ao âmbito hospitalar e salienta-se, sobretudo, os atendimentos emergenciais que externam possibilidades resolutivas concretas. Nessa lógica paradigmática, a porta de entrada para os casos graves confluem para a média e/ou alta complexidade e a população demanda os múltiplos suportes advindos desses serviços especializados.

É importante esta integração, saúde e conselho, pois várias vezes chegam aos hospitais casos que competem à intervenção do conselho (M2-CT2).

Essa importância também foi evidenciada em uma pesquisa realizada na região norte do Rio Grande do Sul, onde os profissionais do serviço hospitalar, ao atender crianças e adolescente em situação de violência intrafamiliar, realizam a comunicação e alguns encaminham para o Ministério Público, Conselho Tutelar e Assistência Social do hospital. A realização de encaminhamentos intersetoriais atesta a necessária parceria entre os órgãos da Rede de Proteção e, nessa ótica, possibilita que os envolvidos rompam o silêncio que subjaz os casos de violência, favorecendo atendimento e acom- 
panhamento adequados para a criança, adolescente e sua família (Cocco, Silva e Jahn, 2010).

Ressalta-se a existência de cenários que buscam efetivar a intersetorialidade para que se cumpram os direitos assegurados às crianças e aos adolescentes, em situação de violência intrafamiliar e outras modalidades. Em contraponto, os serviços hospitalares e as emergências, que concentram os atendimentos dessa casuística, ainda não qualificaram seus processos de trabalho de modo integral e orientado pelas diretrizes políticas e documentos protocolares disponíveis à gestão do setor saúde.

Salienta-se que o processo de trabalho em saúde frente à violência deve ir além do aspecto técnico. Torna-se imprescindível que o profissional tenha uma formação política, capaz de transpor o olhar biomédico para um cuidado integral que dialogue com as demandas sociais, preconizadas nos dispositivos legais (Brasil, 1988, 1990, 2014).

A população procura constantemente esses serviços, e isso respalda a atuação dos profissionais no enfrentamento da violência intrafamiliar. A essa atuação, então, deve intercalar-se a do conselho tutelar, órgão que dará continuidade ao caso e intermediará a apuração de responsabilidades delitivas.

Importante que esses casos sejam acompanhados pelo conselho tutelar com protocolos de atendimento, notificação e encaminhamento. Estudo reitera que os trabalhadores de saúde muitas vezes conhecem essa importância, mas algumas instituições não disponibilizam ferramentas à realização de parcerias (Galvão e Dimenstein, 2010).

Além desse caminho, existem os casos que chegam até o conselho tutelar, e demandam avaliação desses profissionais para que a assistência seja prestada pelos serviços que compõem a rede de proteção. Vale salientar que os conselheiros sabem da importância de cada órgão, porém o setor saúde é um dos que menos encaminham ao conselho tutelar, devido a inúmeras razões, inclusive a não padronização dos registros e as dificuldades de comunicação (Deslandes et al., 2006).

Apesar de os participantes do estudo reconhecerem a importância e a necessidade desse trabalho intersetorial, identificaram-se, no decorrer da investigação, fatores que afetam a concretização de uma parceria sólida, o que compromete a implementação de políticas públicas que assegurem os direitos de crianças e adolescentes.

Esses fatores podem ter sua gênese na sobreposição de desafios que transitam entre as produções de práticas fragmentadas, e desconhecimento ou conhecimento incipiente das políticas sociais que, por sua vez, reverberam em uma gestão frágil e descontextualizada dos dispositivos legais que circunscrevem o enfrentamento das violências contra grupos vulneráveis.

Concretizar a parceria entre o conselho tutelar e o setor saúde facilitaria e tornaria eficaz a comunicação e a articulação das ações, criar-se-iam espaços 
de diálogo e tentar-se-ia encontrar mecanismos para padronizar o atendimento e acompanhamento, o que daria visibilidade à questão da violência intrafamiliar e, consequentemente, possibilidades resolutivas.

\section{Inexistência de parceria entre o conselho tutelar e o setor saúde}

Alguns conselheiros, a despeito de reconhecerem o trabalho do setor saúde, expressaram a inexistência dessa parceria, e reforçaram que não se tem e não se vê, mas sustentaram a ideia de que é extremamente necessária. Expressaram que não têm o apoio dos serviços de saúde quando encaminham para o atendimento casos de pessoas em situação de violências e externaram a questão, que se mostra nos fragmentos dispostos:

Necessitamos do apoio dos serviços de saúde, pois sempre há encaminhamentos para saúde (M7-CT1).

É necessária, pois há situações variadas na qual dependemos ou necessitamos de atendimento de profissionais [saúde] (M7-CT4).

Percebe-se que apesar de afirmarem que não existe parceria entre o conselho tutelar e o setor saúde eles reconhecem esta necessidade, visto que o setor saúde é visualizado pela comunidade como porta de entrada para tratamento de lesões, que muitas vezes são oriundas da violência nas relações familiares.

Esse reconhecimento das ações de ambos os órgãos (conselho tutelar de um lado e os serviços de saúde de outro) possibilitaria uma articulação ativa porque desempenham funções complementares, mas, devido a embates como a implementação de políticas públicas comuns (padronização de instrumentos, educação permanente dos profissionais, dentre outros instrumentos de planejamento e gestão), a efetivação da intersetorialidade e o fortalecimento da prevenção e enfrentamento às violências ficam prejudicados.

$O$ reduzido encaminhamento de casos de violência intrafamiliar aos conselhos tutelares, realizado pelo setor saúde, pode relacionar-se ao fato de que os profissionais ainda não assimilaram, em sua totalidade, como demanda que também é deste setor, as diversas formas de violências (sobremodo o componente relativo à intencionalidade).

Outro ponto que pode interferir no referenciamento dos casos de violência é a vinculação do profissional com o território, local em que desenvolve a sua prática e convive com os moradores. Muitas vezes, essas violências eclodem nas comunidades e, no decorrer do atendimento e investigação, aflora o sentimento de medo entre os conselheiros por conviverem com familiares, que, não raro, são apontados como os perpetradores desses casos. 
Apreende-se que a parceria citada no trabalho e descrita por alguns conselheiros tutelares relaciona-se à saúde como um órgão para encaminhamento resolutivo de problema como lesão física, e não como um parceiro para delinear estratégias e tomada de decisão para o enfrentamento e resolução dos casos. É de supor que essa percepção evidencie a visão curativa que os conselheiros tutelares, participantes deste estudo, detêm sobre o setor saúde, o que é reiterado pela literatura (Porto, Bispo Júnior e Lima, 2014; Caron, Lefèvre F. e Lefèvre A., 2015).

O raciocínio clínico categórico, biomédico, de 'lesões objetivadas' é conhecido na evolução dos modelos de atenção à saúde e 'trata' os indivíduos em função do que se vê sem considerar o que sentem ou o que falam. Esta postura impede uma escuta qualificada e dificulta a identificação de agravos complexos e de dificil diagnóstico que, muitas vezes, manifestam-se como 'sintomas indefinidos' (Guedes, Nogueira e Camargo Júnior, 2009).

O que falta para que esse modelo biomédico centralizado na lesão entre em declínio, desenvolva-se e transforme-se em um cuidado integrado, balizado por uma prática social, como priorizam as políticas que norteiam remodelagens da atenção à saúde? Uma discussão sobre o assunto se faz importante para consolidar essa ideia e ampliar olhares institucionais e profissionais no enfrentamento e nas possibilidades de romper o ciclo da violência intrafamiliar que subjuga crianças e adolescentes.

Estudo que apresenta diagnóstico situacional da subnotificação de maus-tratos no contexto da atenção básica em municípios cearenses evoca que a adesão insatisfatória do profissional de saúde para cumprir os dispositivos que legislam sobre o ato notificatório contribui para manter a invisibilidade do problema. Nessa perspectiva, o modo como os serviços e os recursos humanos da saúde articulam os processos de trabalho deve considerar os obstáculos que circunscrevem à efetivação dessa prática (Rolim et al., 2014).

Reconhece-se que para equacionar planejamentos e ações coletivas urge que esses processos sejam ancorados na intersetorialidade. Neste sentido, os atores do Sistema de Garantia de Direito devem buscar uma prática articulada, organizada e estruturada, que dê respostas efetivas no intuito de modificar as concepções do indivíduo, família e comunidade, e evite, com tais ações, a violação de direitos.

Essa estrutura disciplinar reverbera nas práticas cotidianas, pois nos serviços hospitalares os casos que sinalizam situações de violências são conduzidos pela assistência social, quanto à avaliação e comunicação desses casos aos Conselhos Tutelares. Nessa ótica, os profissionais de saúde tendem a ficar à margem da condução e seguimento do processo.

É consenso na literatura que o enfrentamento da violência, principalmente contra a criança e o adolescente, desafia uma intersetorialidade resolutiva (Brasil, 2013; Vieira et al., 2015). Essa incongruência revela que o setor saúde 
ainda 'não se apropriou' da importância que detém ao exercer contribuição ímpar na compreensão do fenômeno, na oferta de uma atenção qualificada e longitudinal, bem como no encaminhamento e acompanhamento de suas vítimas e familiares.

Deste modo, a decisão de notificar não se prende somente à orientação da legislação, mas sim a aspectos de ordem da experiência e formação profissional e de estrutura e articulação da rede de proteção (Rolim et al., 2014).

Por outro lado, estudos apontam debilidades estruturais e dificuldades dos profissionais de saúde em identificar e notificar os casos. Tais práticas são ainda incipientes ao nível da rede de atendimento e ocorrem de forma casual e não sistemática (Moreira et al., 2013). Essas constatações evidenciam o descompasso entre o que é proposto pelos dispositivos legais e pelas políticas públicas de enfrentamento do problema e a efetiva prática dos profissionais do setor saúde (Rolim et al., 2014).

Isso pode ser reflexo da gestão governamental que impossibilita concretizar as diretrizes das políticas públicas, e não oferece condições adequadas de trabalho efetivas para que se fomente o pensar e o agir intersetorial. É preciso que os múltiplos profissionais que atendem e acompanham crianças e adolescentes concebam a violência como uma dinâmica relacional que ocorre no âmbito das famílias, devendo ser considerada nos processos de trabalho.

\section{Considerações finais}

Esse descompasso entre as atuações conjuntas entre conselho tutelar e setor saúde demonstra a importância de uma capacitação na área da violência intrafamiliar, porque os profissionais de saúde possuem uma formação clínica e o conselheiro tutelar atua centrado nos princípios legais que constam no Estatuto da Criança e do Adolescente.

Encontram-se aí, no âmbito da violação dos direitos das crianças e adolescentes, dois tipos de mentalidades e duas linguagens, o que dificulta uma parceria intersetorial, coibindo a soma de esforços e a multiplicação de resultados exitosos. Torna-se um desafio a gestão municipal capacitar profissionais no enfrentamento das violências, fenômeno que exige sensibilidade, conhecimento do problema, do contexto e atuação integrada para viabilizar momentos de reflexão, partilha de experiências e aprendizado.

Alguns conselheiros tutelares criticaram as frágeis parcerias com o setor saúde e identificaram que os municípios não dispõem de estruturas para firmar a intersetorialidade preconizada nos dispositivos legais e assegurar, com qualidade, a proteção integral às crianças e aos adolescentes em situação de violência intrafamiliar. 


\section{Colaboradores}

Samira Valentim Gama Lira realizou todas as etapas da pesquisa e participou da análise, discussão dos dados e redação do artigo. Deborah Pedrosa Moreira e Gerarda Maria Araújo Carneiro realizaram a coleta dos dados e a redação final. Ceci Vilar Noronha colaborou na produção textual e redação do artigo e Luiza Jane Eyre de Souza Vieira atuou na orientação da pesquisa e redação final.

Resumen Tratase de un estudio cualitativo sobre la articulación entre el juzgado de menores y el sector salud durante los años 2013 y 2014. En el estudio participaron 45 consejeros tutelares de la Región Metropolitana de Fortaleza, Ceará, Brasil. Los datos fueron obtenidos por entrevistas semi-estructuradas y analizados según análisis de contenido. Los resultados mostraron falta de colaboración entre el sector salud y judicial. Esta falta de correspondencia entre las actuaciones del consejo tutelar y el sector de la salud demuestra brechas intersectoriales. El diálogo entre el jurídico y el clínico daría lugar a costos más bajos y a acciones más exitosas permitiendo reducir la violencia contra niños y adolescentes.

Palabras clave acción intersectorial; defensa de los niños y adolescentes; sistema único de salud; violencia.

\section{Notas}

${ }^{1}$ Prefeitura de Vitória da Conquista, Centro de Referência em Saúde do Trabalhador, Bahia, Brasil. Universidade de Fortaleza, Fortaleza, Ceará, Brasil.

<samiralira@unifor.br>

Correspondência: Avenida Washington Soares, 1.321, bloco C, sala C04, Edson Queiroz, CEP 60811-905, Fortaleza, Ceará, Brasil.

${ }^{2}$ Centro Universitário Christus, Fortaleza, Ceará, Brasil.

$<$ deborahpm@gmail.com>

${ }^{3}$ Centro Universitário Christus, Fortaleza, Ceará, Brasil.

<gerarda_gg@hotmail.com>

${ }^{4}$ Universidade Federal da Bahia, Instituto de Saúde Coletiva, Salvador, Bahia, Brasil. <ceciavilar@gmail.com>

${ }^{5}$ Universidade de Fortaleza, Programa de Pós-graduação em Saúde Coletiva, Fortaleza, Ceará, Brasil.

<janeeyre@unifor.br>

${ }^{6}$ Este artigo relata parte do estudo da tese de doutorado intitulada Conselheiros Tutelares: saberes e práticas no enfrentamento à violência intrafamiliar contra crianças e adolescentes, de autoria de Samira Valentim Gama Lira, defendida em 2014 no âmbito do Doutorado em Saúde Coletiva da Associação Ampla UECE/UFC/Unifor, tendo sido aprovado no Comitê de Ética e Pesquisa da Universidade de Fortaleza sob o parecer n. 456.783/2013, não havendo conflito de interesse. 


\section{Referências}

BARDIN, Laurence. Análise de conteúdo. Lisboa: Edições 70, 2011.

BRASIL. Constituição da República Federativa do Brasil de 1988. Diário Oficial da União, Brasília, DF, 5 out. 1988. Seção I, n. 191A, p. 1-32. Disponível em <http://www.planalto. gov.br/ccivil_03/Constituicao/DOUconstituicao88.pdf > Acesso em: 5 jun. 2012.

BRASIL. Lei n. 8.069, de 13 de julho de 1990. Dispõe sobre o Estatuto da Criança e do Adolescente e dá outras providências. Diário Oficial da União, Brasília, DF, 16 jul. 1990. Seção I, p. 13.563. Disponível em < https:// www.planalto.gov.br/ccivil_03/leis/L8069. htm\#art267> Acesso em: 5 jun. 2012.

BRASIL. Ministério da Saúde. Política Nacional de Redução da Morbimortalidade por Acidentes e Violências: Portaria GM/MS n. 737. Diário Oficial da União, Brasília, DF, 18 maio 2001. Seção 1e, n. 96. Disponível em < http:// bvsms.saude.gov.br/bvs/publicacoes/politica_ reducao_morbimortalidade_acidentes_2ed > . Acesso em: 5 jun. 2012.

BRASIL. Ministério da Saúde. Secretaria de Políticas de Saúde. Violência intrafamiliar: orientações para prática em serviço. Brasília, 2002. 96p.

BRASIL. Ministério da Saúde. Secretaria de Atenção à Saúde. Departamento de Atenção Básica. Vigilância em Saúde: Dengue, Esquistossomose, Hanseníase, Malária, Tracoma e Tuberculose. 2. ed. rev. Brasília, 2008. 119p.

BRASIL. Ministério da Saúde. Secretaria de Atenção à Saúde. Departamento de Atenção Básica. Por uma cultura da paz, a promoção da saúde e a prevenção da violência. Brasília, 2009. 46p.

BRASIL. Ministério da Saúde. Secretaria de Atenção à Saúde. Departamento de Ações Programáticas Estratégicas. Linha de cuidado para a atenção integral à saúde de crianças, adolescentes e suas famílias em situação de violências: orientação para gestores e profissionais de saúde. Brasília, 2010. 101p.

BRASIL. Portaria n. 104, de 25 de janeiro de 2011. Define as terminologias adotadas em legislação nacional, conforme o disposto no Regulamento Sanitário Internacional 2005 (RSI 2005), a relação de doenças, agravos e eventos em saúde pública de notificação compulsória em todo o território nacional e estabelece fluxo, critérios, responsabilidades e atribuições aos profissionais e serviços de saúde. Saúde Legis - Sistema de Legislação da Saúde. Diário Oficial da União, Brasilia, DF, 26 jan., 2011. Seção 1, n. 18, p. 37. 201la. Disponível em: < http://bvsms.saude.gov. br/bvs/saudelegis/gm/2011/prt0104_25_01_2011. html>. Acesso em: 5 jun 2012.

BRASIL. Ministério da Saúde. Secretaria de Vigilância em Saúde. Departamento de Análise de Situação de Saúde. Viva: instrutivo de notificação de violência doméstica, sexual e outras violências. Brasília, 2011b. 72p.

BRASIL. Secretaria de Direitos Humanos. Plano Nacional de Enfrentamento da Violência Sexual contra Crianças e Adolescentes. Brasilia, 2013. 50p.

BRASIL. Ministério da Saúde. Secretaria de Atenção à Saúde. Departamento de Ações Programáticas e Estratégicas. Metodologias para o cuidado de crianças, adolescentes e famílias em situação de violências. Brasília, 2014. 86p.

CARON, Eduardo; LEFÈVRE, Fernando; LEFÈVRE, Ana M. C. Afinal, somos ou não somos uma sociedade de consumo? Consequências para a saúde. Ciência \& Saúde Coletiva, Rio de Janeiro, v. 20, n.1, p. 145-153, jan. 2015.

COCCO, Marta; SILVA, Ethel B.; JAHN, Alice C. Abordagem dos profissionais de saúde em instituições hospitalares a crianças e adolescentes vítimas de violência. Revista Eletrônica de. Enfermagem, Goânia, v. 12, n. 3, p. 491497, ago.-set. 2010. 
CONSELHO NACIONAL DOS DIREITOS DA CRIANÇA E DO ADOLESCENTE - CONANDA. Conselho Municipal dos Direitos da Criança e do Adolescente e Conselho Tutelar. Brasília: Conanda, 2007.

COSTA, Dayse K. G. C. et al. Concepções e práticas dos profissionais de saúde acerca da violência intrafamiliar contra crianças e adolescentes. Trabalho, Educação e Saúde, Rio de Janeiro, v. 13, supl. 2, p. 79-95, 2015.

DESLANDES, Suely F. et al. Caracterização diagnóstica dos serviços que atendem vítimas de acidentes e violências em cinco capitais brasileiras. Ciência \& Saúde Coletiva, Rio de Janeiro, v. 11, supl. 0, p. 1.279-1.290, 2006.

ORGANIZAÇÃO DAS NAÇÕES UNIDAS. Declaração Universal dos Direitos Humanos. 10 de dezembro de 1948. Assembleia Geral das Nações Unidas, resolução 217A. Disponível em: < http://unesdoc.unesco.org/images/0013/001394/139423por. pdf>. Acesso em: 23 jan. 2016.

ORGANIZAÇÃO DAS NAÇÕES UNIDAS. Declaração Universal dos Direitos das Crianças. 20 nov. 1959. Disponível em: <http://bvsms.saude. gov.br/bvs/publicacoes/declaracao_universal_ direitos_crianca.pdf $>$ Acesso em: 23 jan. 2016.

GADELHA, Carlos A. G.; MALDONADO, José; COSTA, Laís S. O complexo produtivo da saúde e sua relação com o desenvolvimento: um olhar sobre a dinâmica da inovação em saúde. In: GIOVANELLA, Lígia et al. (org.). Políticas e sistemas de saúde no Brasil. 2. ed. Rio de Janeiro: Editora Fiocruz, 2012, p. 209-238.

GALVÃO, Vanessa A. B. M.; DIMENSTEIN, Magda. A violência e o Protocolo de Notificação como analisadores dos processos de trabalho da Atenção Primária em Saúde. Cadernos Brasileiros de Saúde Mental, Florianópolis, v. 2, n. 3, p. 01-21, ago.-set. 2010.

GUEDES, Carla R.; NOGUEIRA, Maria I.; CAMARGO JÚNIOR, Kenneth R. C. Os sofredores de sintomas indefinidos: um desafio para a atenção médica. Physis: Revista de Saúde Coletiva [on-line], Rio de Janeiro, v. 19, n. 3, p. 797-815, jan.-fev. 2009.
GONÇALVES, Cláudia F. G. et al. Atuação em rede no atendimento ao adolescente vítima de violência: desafios e possibilidades. Texto Contexto Enfermagem, Florianópolis, v. 24, n. 4, p. 976-83, out-dez. 2015.

LIMA, Maria C. C. S. et al. Atuação profissional da Atenção Básica de Saúde face à identificação e notificação da violência infantojuvenil. Revista Baiana de Saúde Pública, Salvador, v. 35, supl. I, p.118-137, jan.-jun. 2011.

MOREIRA, Gracyelle A. R. et al. Instrumentação e conhecimento dos profissionais da equipe saúde da família sobre a notificação de maus-tratos em crianças e adolescentes. Revista Paulista de Pediatria, São Paulo, v. 31, n. 2, p. 223-230, jun. 2013.

PORTO, Roberta T. S.; BISPO JÚNIOR, José P.; LIMA, Elvira C. Violência doméstica e sexual no âmbito da Estratégia de Saúde da Família: atuação profissional e barreiras para o enfrentamento. Physis: Revista de Saúde Coletiva [on-line], Rio de Janeiro, v. 24, n. 3, p. 787-807, fev.-mar. 2014.

ROLIM, Ana C. A. et al. Subnotificação de maus-tratos em crianças e adolescentes na Atenção Básica e análise de fatores associados. Saúde em Debate, Rio de Janeiro, v. 38, n.103, p. 794-804, set.-out., 2014.

SECRETARIA DE SAÚDE DO ESTADO DO CEARÁ. Sesa prepara profissionais para atendimento às vítimas de violência. 2011. Disponível em: <http://www.saude.ce.gov.br/index.php/ noticias/44996-sesa-prepara-profissionaispara-atendimento-as-vitimas-de-violencias > Acesso em: 19 fev. 2016.

VIEIRA, Luiza J. E. S. et al. Relatos de gestores da Assistência Social, Educação e Segurança Pública sobre o enfrentamento da violência. Cadernos de Saúde Coletiva, Rio de Janeiro, v. 23, n. 3, p. 231-238, set. 2015.

Recebido em 09/03/2016.

Aprovado em 30/03/2017. 